\title{
Hydraulic Conductivity of Bentonite Grouted Sand
}

\author{
H. Hwang ${ }^{1}$, J. Yoon ${ }^{2}$, D. Rugg ${ }^{2}$ and C.S. El Mohtar ${ }^{3}$, PhD, A.M. ASCE \\ ${ }^{1}$ Lecturer, Dept. of Civil Engineering and Environmental Sciences, Korea Military \\ Academy, Seoul, South Korea \\ ${ }^{2}$ Graduate student, Department of Civil, Architectural and Environmental \\ Engineering, The University of Texas at Austin,, Austin, TX 78712-0280 \\ ${ }^{3}$ Assistant Professor, Department of Civil, Architectural and Environmental \\ Engineering, The University of Texas at Austin,, Austin, TX 78712-0280; PH (512) \\ 471-3695; FAX (512) 471-6548; email: ElMohtar@mail.utexas.edu
}

\begin{abstract}
The yield stress and viscosity of bentonite suspensions treated with Sodium Pyrophosphate (SPP) were measured to investigate the applicability of modified bentonite suspensions as a permeation grout. The yield stress and viscosity were significantly reduced with the addition of Sodium Pyrophosphate (SPP). The main advantage of using SPP is the temporary nature of the reduction in yield stress and viscosity; both parameters increase with time and exceed the values of the original suspension without the SPP. Permeability tests were conducted to verify the effectiveness of the bentonite suspensions in decreasing the hydraulic conductivity of the sand. Permeated samples were prepared with clean sand and bentonite using 7.5, 10 , and $12 \%$ bentonite suspensions. The results showed that hydraulic conductivities of the sand decreased by $4,4.5$ and 5 orders of magnitude with grout bentonite contents of $7.5 \%, 10 \%$ and $12 \%$, respectively. These findings suggest the possible application of Sodium Pyrophosphate (SPP) treated bentonite suspensions in permeation grouting for controlling hydraulic conductivity.
\end{abstract}

\section{INTRODUCTION}

Permeation grouting is a conventional technique to reduce hydraulic conductivity and to strengthen soil deposits without disturbing the original soil structure (Weaver 1993; Chun et al. 2006; Kazemain and Huat 2009). Haldavnekar et al (2003), El Mohtar et al (2008) and Rugg (2010) specifically studied the possibility of using bentonite grouts to improve soil performance under seismic loading. Although cement grouts have been widely used in permeation grouting and many previous works have been published, groundwater contamination may be caused by the addition of cement to the groundwater (Metcalfe and Walker 2004). Bentonite grouts represent a viable alternative because of their environment friendliness and long term safety (Chegbeleh et al. 2009). However, the application of concentrated bentonite suspensions in permeation grouting has been limited due to the high viscosity and yield stress of the suspensions which results in very low grout penetration distances. Previous researchers have shown that introducing ionic 
additives such as sodium hydroxide, sodium silicate, and sodium pyrophosphate reduce the viscosity and yield stress of bentonite suspensions (Abend and Lagaly. 2000, Gonzales and Martin-Vivaldi 1963, and Jessen and Turan 1961), resulting in increased mobility. Moreover, Tchillingarian (1952) reported that sodium pyrophosphate has a greater capacity to disperse clay particles than sodium hydroxide and sodium silicate. New port bay clay with sodium hexametaphosphate displayed flocculation, but showed complete de-flocculation with sodium hydroxide and gum ghatti after 3 days. This implies that bentonite suspensions treated with sodium pyrophosphate will have low enough initial viscosity and yield stress to be permeated into soils and high enough viscosity and yield stress to prevent flow after setting.

Once the suspensions are permeated into a soil, the hydraulic conductivity of the soil decreases significantly. Although the hydraulic conductivity of the bentonite grouted sands has not been studied extensively, previous research with SandBentonite Mixtures (SBM) show the effectiveness of bentonite in reducing the hydraulic conductivity of sands. Chapui (2000) showed that the hydraulic conductivity of sand $\left(10^{-2} \mathrm{~cm} / \mathrm{sec}\right)$ was reduced to $10^{-6} \mathrm{~cm} / \mathrm{s}$ with $5 \%$ dry bentonite (by sand mass). Abichou (2000) also reported that compacted sand bentonite mixtures reduce the hydraulic conductivity of sand by six (6) orders of magnitude. Recently, Castelbaum and Shakelford (2009) used bentonite suspensions for the treatment of a chlorine contaminated soil deposit and reported that the hydraulic conductivity ranged from $10^{-7}$ to $10^{-4} \mathrm{~cm} / \mathrm{s}$. The objective of this study is to investigate the change in yield stress and viscosity due to the addition of Sodium pyrophosphate through rheological testing, and to measure hydraulic conductivity of the grouted sands. This research will show the possible application of bentonite suspensions in permeation grouting.

\section{EXPERIMENTAL PROGRAM}

\section{Materials.}

Ottawa sand (ASTM graded C778) was used in this study. This sand is classified as SP based on a USCS Classification. Table 1 summarizes the index properties of Ottawa sand based on ASTM standards. Wyoming sodium-bentonite grade CP-200 was used to prepare suspensions. The bentonite contains at least $70 \%$ fine particles that are smaller than $0.075 \mathrm{~mm}$, and it swells freely at a minimum ratio of $8 \mathrm{ml} / \mathrm{g}$. Bentonite properties are summarized in Table 2 (Mitchell and Soga 1976). Since raw bentonite includes impurities such as plagioclase feldspar, orthoclase, and muscovite minerals (Abend and Lagaly 2000), the raw bentonite was sieved through a No.200 sieve to minimize the impurities and their effects on the results (Clarke 2008). The specific gravity of the bentonite was 2.7. Figure 1 shows the particle size distribution of Ottawa sand and sieved bentonite. Commercially available Sodium

Pyrophosphate (SPP) decahydrate $\left(\mathrm{Na}_{4} \mathrm{P}_{2} \mathrm{O}_{7} \cdot 10 \mathrm{H}_{2} \mathrm{O}\right)$ has a specific gravity of 1.8 , Molecular weight of 446.06, and the $\mathrm{pH}$ of a $5 \%$ SPP solution measured using a JENCO $60 \mathrm{pH}$ meter was 9.5. 
Table 1. Properties of Ottawa sand

\begin{tabular}{c|c|c|c}
\hline Gs & 2.65 & $\mathrm{Cu}$ & 1.61 \\
\hline $\mathrm{e}_{\min }$ & 0.50 & $\mathrm{Cc}$ & 1.07 \\
\hline $\mathrm{e}_{\max }$ & 0.76 & $\mathrm{D}_{10}(\mathrm{~mm})$ & 0.23 \\
\hline $\mathrm{USCS}$ & $\mathrm{SP}$ & $\mathrm{D}_{60}(\mathrm{~mm})$ & 0.37 \\
\hline
\end{tabular}

Table 2. Properties of Wyoming bentonite (modified after Mitchell and Soga 1976)

\begin{tabular}{c|c|c|c}
\hline PL & $35 \%$ & CEC & 80 to $150 \mathrm{meq} / 100 \mathrm{~g}$ \\
\hline LL & $190 \%$ to $1160 \%$ & Specific area & 700 to $800 \mathrm{~m}^{2} / \mathrm{g}$ \\
\hline Initial water content & $8.3 \%$ & Swelling capacity & $8 \mathrm{ml} / \mathrm{g}$ \\
\hline
\end{tabular}

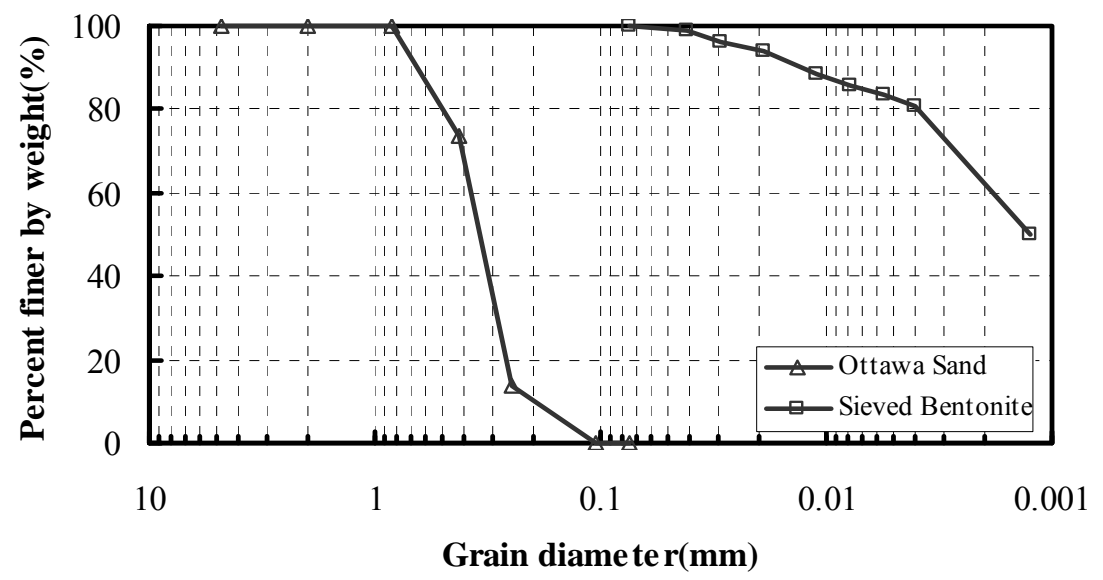

Figure 1. Grain size distribution of Ottawa sand and sieved bentonite.

\section{Testing methods}

\section{Rheological tests}

The yield stress and viscosity of the bentonite suspensions were measured using an Anton Paar MCR301 rheometer. Figure 2 shows a schematic of the rheometer and measuring system used in this study. Vane and cup geometry was selected to estimate yield stresses at a specific resting time in order to avoid severe disturbance in samples when using the traditional cone and plate setup. The vane consisted of six blades $1 \mathrm{~mm}$ in thickness and $16 \mathrm{~mm}$ in length. The radius of the vane was $11 \mathrm{~mm}$. The bentonite grout was placed in a cup with a $3.46 \mathrm{~mm}$ gap between the blades and the cup. Bentonite suspensions were mixed with a Hamilton Beach high speed mixer. The concentration of the bentonite suspensions was calculated as the mass of bentonite divided by the total mass of the suspension. The initial water content of the bentonite was taken into account for this calculation.

A 5\% SPP solution was prepared and a fixed amount of SPP solution was added to bentonite suspensions based on a desired concentration of SPP. The concentration of SPP was calculated as the mass of SPP divided by the mass of 
bentonite. Mixing of the bentonite suspensions was conducted with three steps. Each step consisted of 5 minutes of high speed mixing followed by manual scraping of the sides and base of the mixing cup to remove bentonite flocs attached to the cup. For samples rested for extended periods of time, the cups were tightly sealed and mineral oil was added on top of the bentonite gout to prevent any evaporation from the samples. End effects of the vane were considered small enough to ignore for all practical purposes (Barnes and Carnali 1990).

All rheological tests were performed at a room temperature of $22^{\circ} \mathrm{C}$. The yield stress and viscosity of the bentonite suspensions were measured using the stress ramp technique, which is a stress controlled test. In this test, a stepwise stress was applied in pre-determined intervals and the corresponding shear rate was recorded, resulting in flow curves. The samples were rested for 2 min after inserting the vane to provide a consistent initial condition. Data was recorded at $12 \mathrm{sec}$ intervals and a ramp rate of $3 \mathrm{~Pa} /$ step was applied.

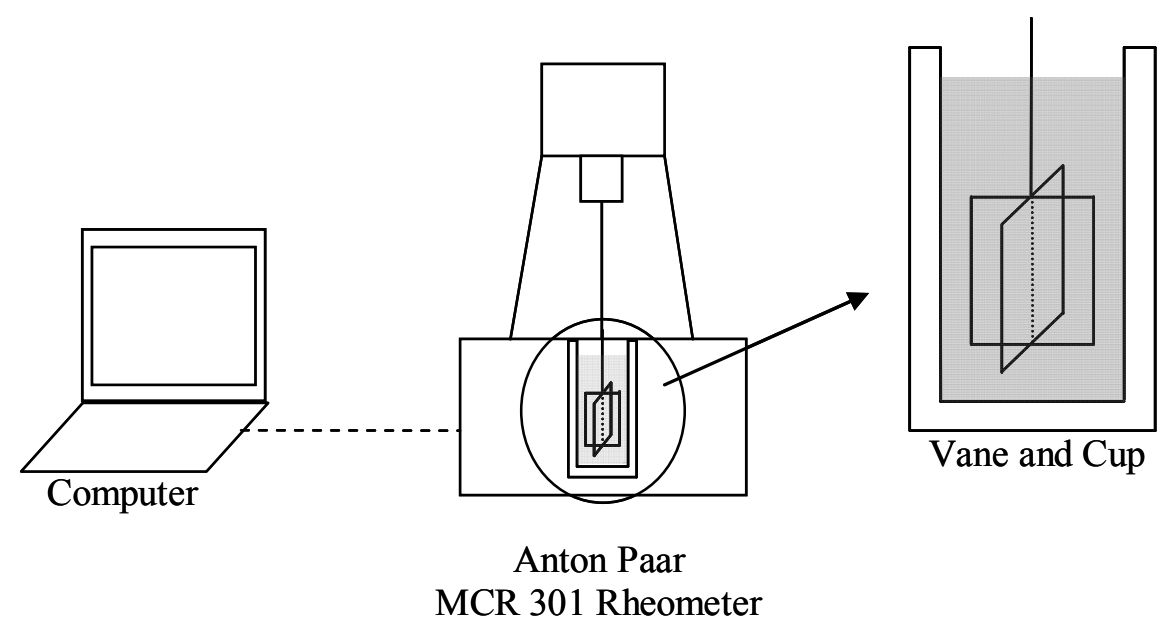

Figure 2. Schematic of Rheological test setup.

\section{Hydraulic conductivity Tests}

Figure 3 displays the injection setup for producing grouted specimens. A permeation cell consisting of 3 separate cylinders was manufactured to prepare grouted specimens for hydraulic conductivity tests. The mold can be disassembled and the middle section of the mold can be trimmed to produce the grouted sand specimen the for the hydraulic conductivity tests. The sand was air pluviated into the cell and saturated from bottom to top with a pressure of $7 \mathrm{kPa}$ to remove air bubbles in the specimen (ASTM .D4320/D4320M-09). A filter material consisting of a layer of 1" coarse sand $(1.2 \mathrm{~mm}<\mathrm{D}<1.75 \mathrm{~mm})$ on top of a layer of 1 " pea gravel (D > $4.75 \mathrm{~mm}$ ) was placed at the top and bottom of the sand column to help produce a uniform distribution of bentonite throughout the sand.

Bentonite suspensions for grouting were prepared in the same manner as described for the rheological tests. The bentonite suspensions were injected into the sand column using a peristaltic pump with a constant flow rate of $1.67 \mathrm{~cm}^{3} / \mathrm{sec}$. Final pressures were limited to $140 \mathrm{kPa}$ to prevent any changes in the sand fabric. The 
specimens were allowed to rest for 24 hours after permeation, and then the middle of the specimens was carefully trimmed with a wire saw, resulting in a specimen with a diameter of $7 \mathrm{~cm}$ and a height of $3.8 \mathrm{~cm}$. Two (2) to two and half (2.5) pore volumes of grout were flushed through each specimen to increase the uniformity of the grouted sand. Moreover, this indicates that the treated bentonite grouts can have a high penetration distance which will be critical for large scale applications.

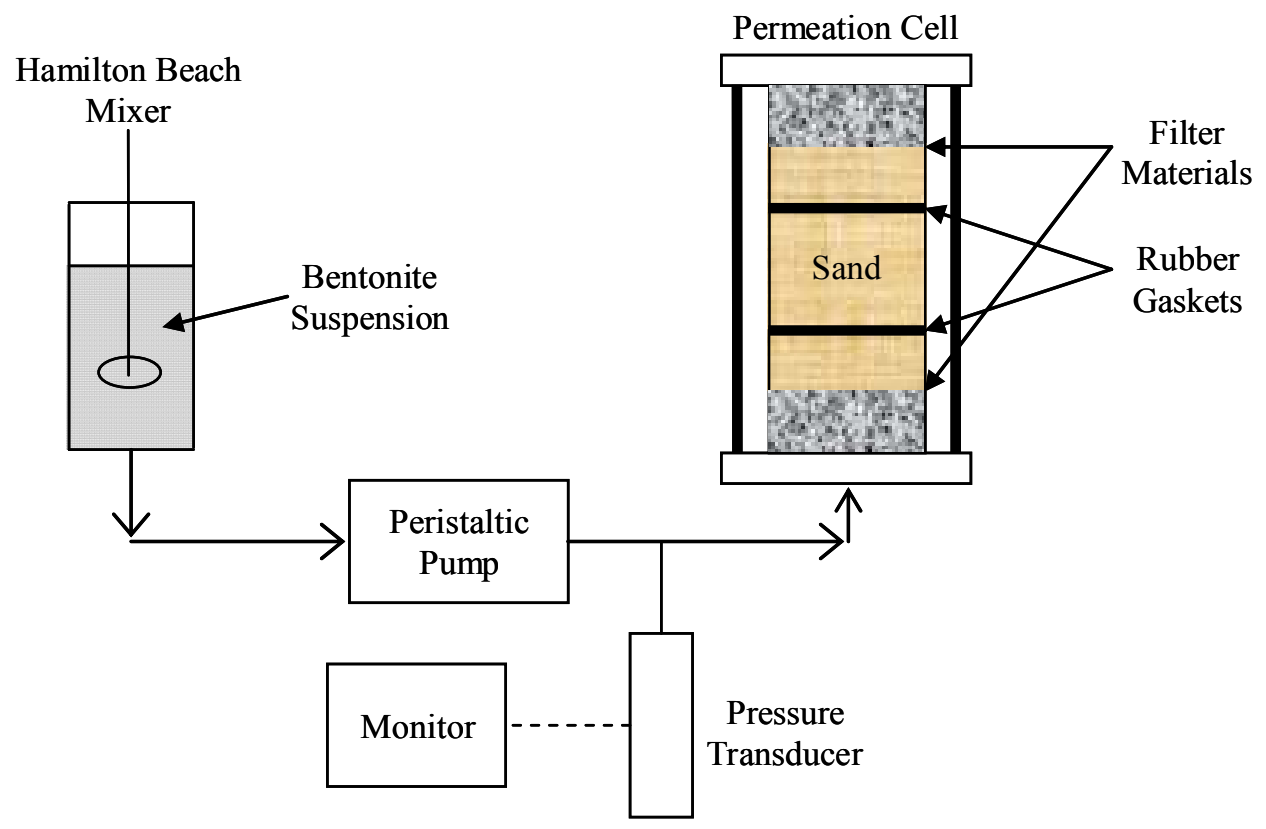

Figure 3. Schematic of injection and sample preparation setup.

Figure 4 depicts a schematic of the hydraulic conductivity tests. After trimming the middle section of the permeation cell, the grouted sand specimen was assembled with a top and bottom plate to measure hydraulic conductivity. One filter paper was placed on the top and on the bottom of the specimens. A backpressure of $300 \mathrm{kPa}$ was applied to increase the degree of saturation of the specimen. After the backpressure saturation stage, a falling and rising head (ASTM 5856-95) test was performed with a hydraulic gradient of 5 to 40 (depending on the estimated hydraulic conductivity of the samples). The amount of water flow and head difference was measured using partial differential transducers (Validyne Engineering, DP15). After the hydraulic conductivity tests were concluded, the bentonite contents at different sections of the specimens were measured by a wet sieve analysis (ASTM 117). The method was slightly modified to measure the dry weight of sand instead of direct measurement of the weight of bentonite. Although this method have some limitations due to possible sources of error in small mass measurements affecting measured bentonite contents, Hwang (2010) reported that this method can estimate bentonite contents with relatively good accuracy (standard deviation from \pm 0.04 to $\pm 0.15 \%$ ). 


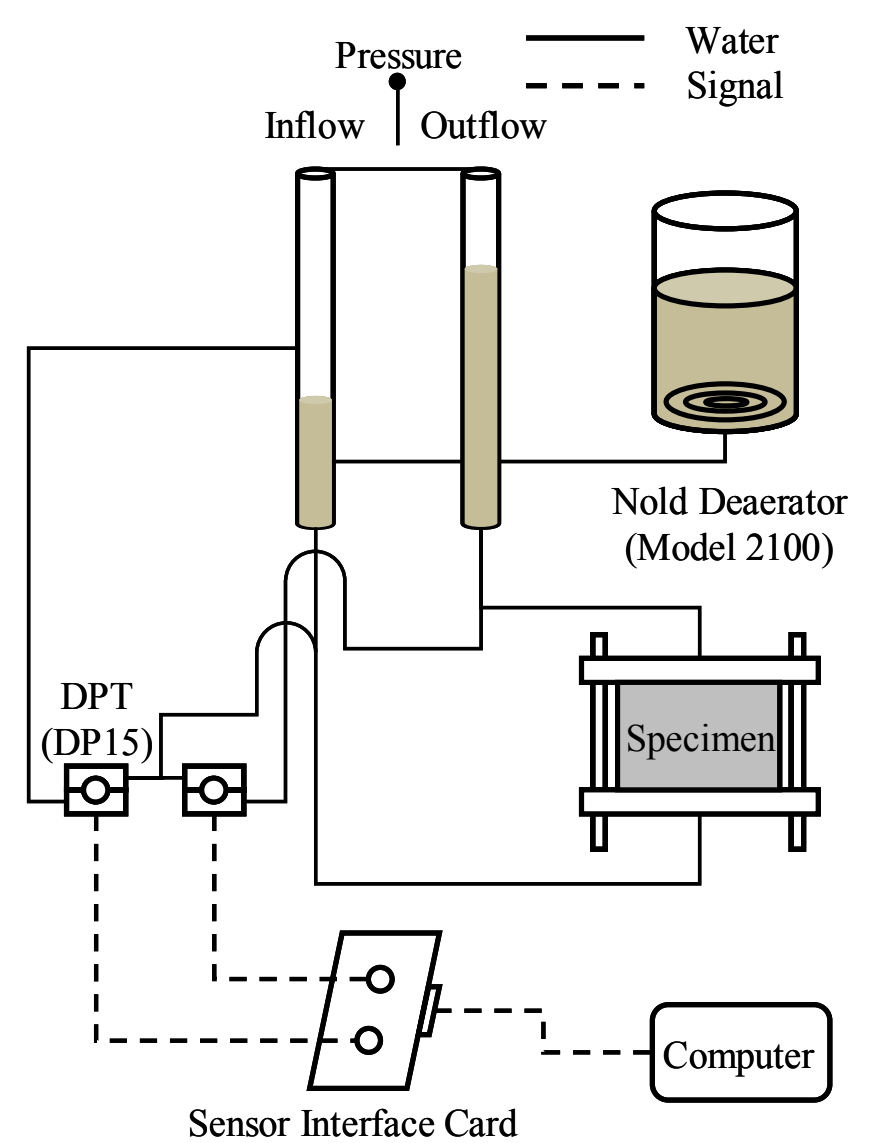

(UPC 2100)

Figure 4. Schematic of hydraulic conductivity test setup.

\section{RESULTS AND ANALYSIS}

\section{Rheology of bentonite suspensions}

Yield stress and viscosity are critical parameters for determining whether a suspension can be successfully permeated through a soil or not. Yield stress, which is defined as a shear stress to initiate the flow of a fluid, was determined by the $\log \gamma$ $\log \tau$ method (Zhu et al. 2001) as the intersection between the initially linear portion of the curve and the plateau. If no plateau was present, then this indicates a fluid with zero yield stress. Figure 5 shows a $\log \gamma-\log \tau$ plot for treated and untreated $7.5 \%$ suspensions. The addition of $1 \%$ of SPP to the $7.5 \%$ bentonite suspensions produced approximately zero yield stress. The variation of viscosity variation with the addition of SPP is displayed in Figure 6. Similar to yield stress, viscosity decreased with SPP addition. However, the degree of reduction in viscosity was different for each shear rate because viscosity is a function of the shear rate. Because of the thixotropic nature of bentonite, the yield stress and viscosity gradually increased with time. Figure 7 presents the increase in yield stress with time. The percentages of SPP required to generate zero yield stress for $10 \%$ and $12 \%$ bentonite suspensions were determined to be $3 \%$ and $4 \%$ respectively. 


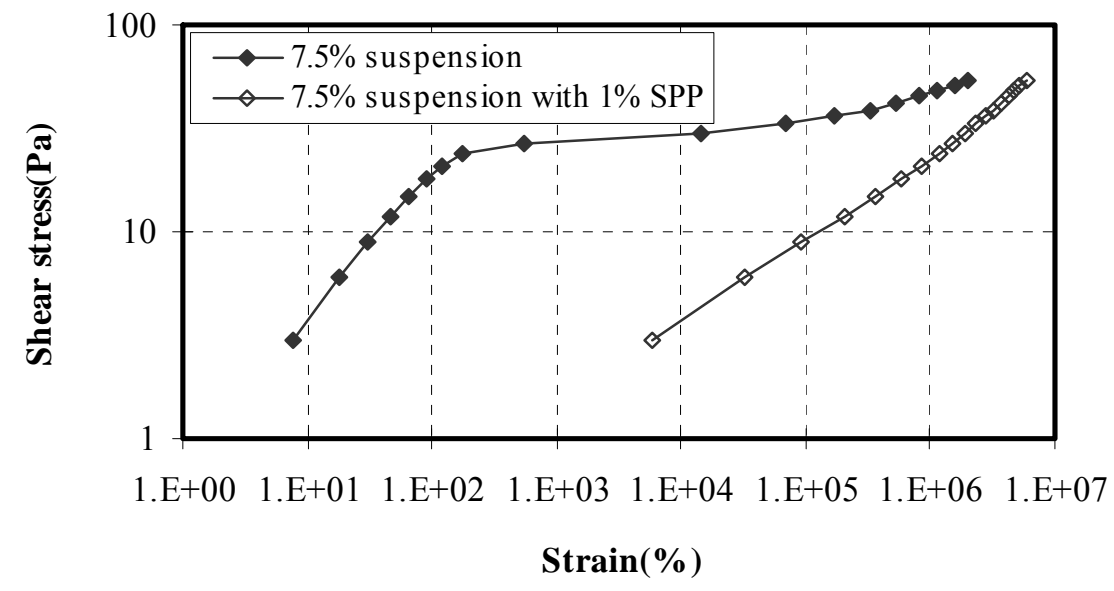

Figure 5. Shear stress-strain curves for $7.5 \%$ bentonite suspensions with 0 and $1 \%$ SPP.

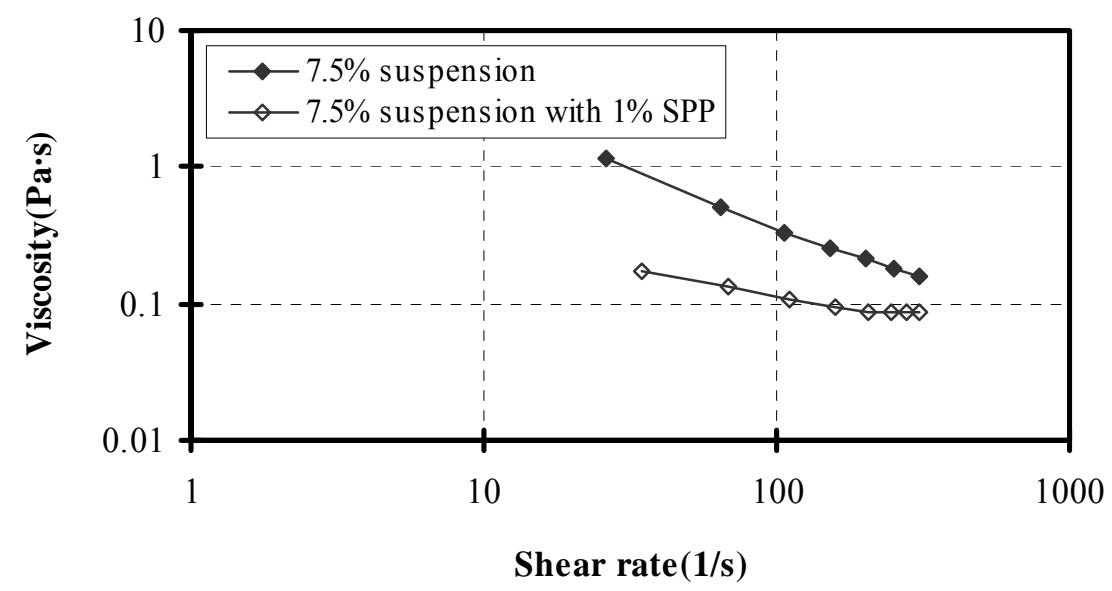

Figure 6. Viscosity-shear rate curves for $7.5 \%$ bentonite suspensions with 0 and $1 \%$ SPP.

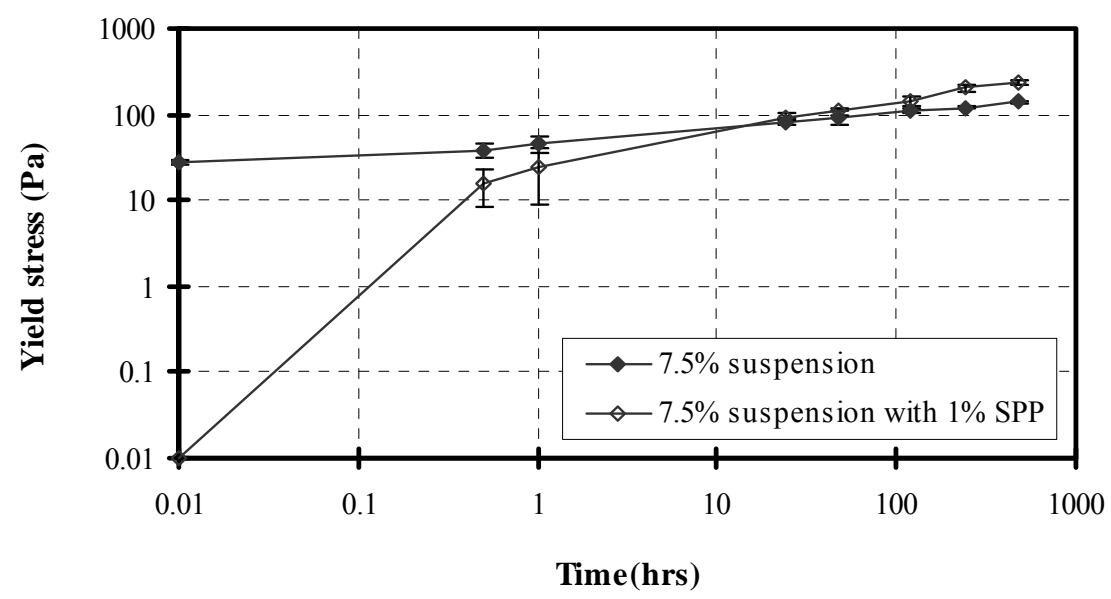

Figure 7. Thixotropy of $7.5 \%$ bentonite suspensions with 0 and $1 \%$ SPP. 


\section{Hydraulic conductivity of the grouted sand}

Figure 8 shows the hydraulic conductivity of the grouted sand based on the concentrations of suspensions flushed through it. All the sands were prepared at a similar relative density (25-30\%) before saturation/permeation and the relative density did not change significantly throughout the test. The hydraulic conductivity of the sand is $0.07 \mathrm{~cm} / \mathrm{s}$ and the hydraulic conductivity was reduced by $4,4.5$, and 5 orders of magnitude after being permeated with 7.5 (1\%), 10 (3\%) and 12\% (4\%) bentonite suspensions, respectively (the numbers between the parentheses indicate the percentage of SPP).

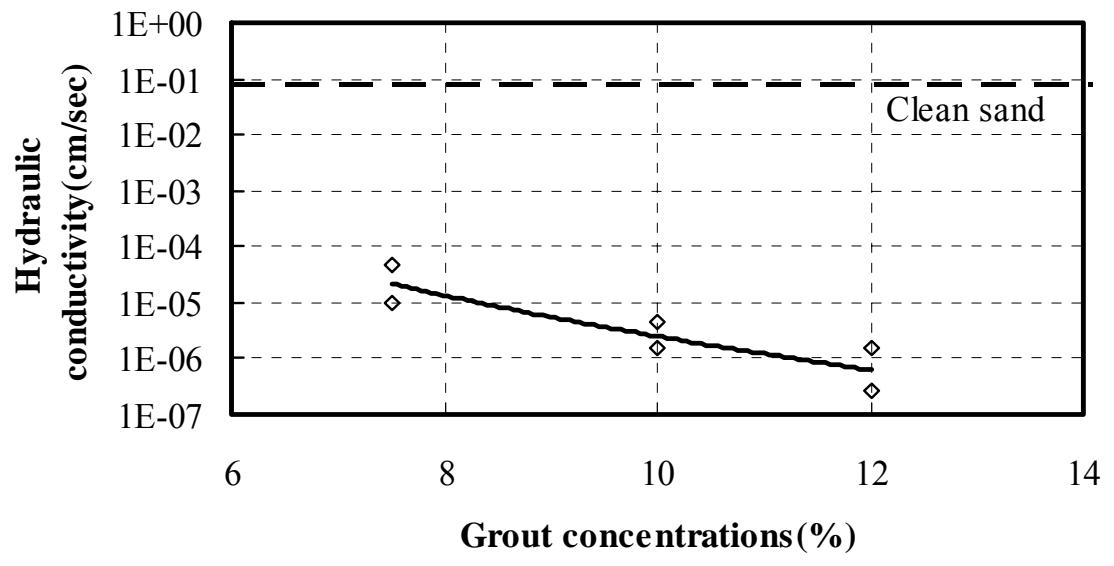

\section{Figure 8. Hydraulic conductivity of the grouted sand with concentrations of injected suspensions.}

Figure 9 shows the hydraulic conductivity of the grouted sand with measured bentonite contents. For reference, the figure also includes the results for clean sand and for SBMs prepared through thorough mixing of the same sand, bentonite and water (Hwang 2010). The values from Hwang (2010) present a lower bound for the hydraulic conductivity of the grouted sand. The addition of SPP allows for permeating high concentration suspensions into the sand, resulting in bentonite contents up to $4 \%$ and a reduction in hydraulic conductivity up to 6 orders of magnitude. The hydraulic conductivity of the grouted sand followed the same trend as that of premixed SBMs indicating the applicability of treated bentonite grouts as a measure for reducing the hydraulic conductivity of sands. The difference in the hydraulic conductivity values at the same bentonite content can be a result of uneven distribution of the grout across the permeated sand; more specifically, the leakage along the sides of the permeation mold where the grout did not completely flush the water out. 


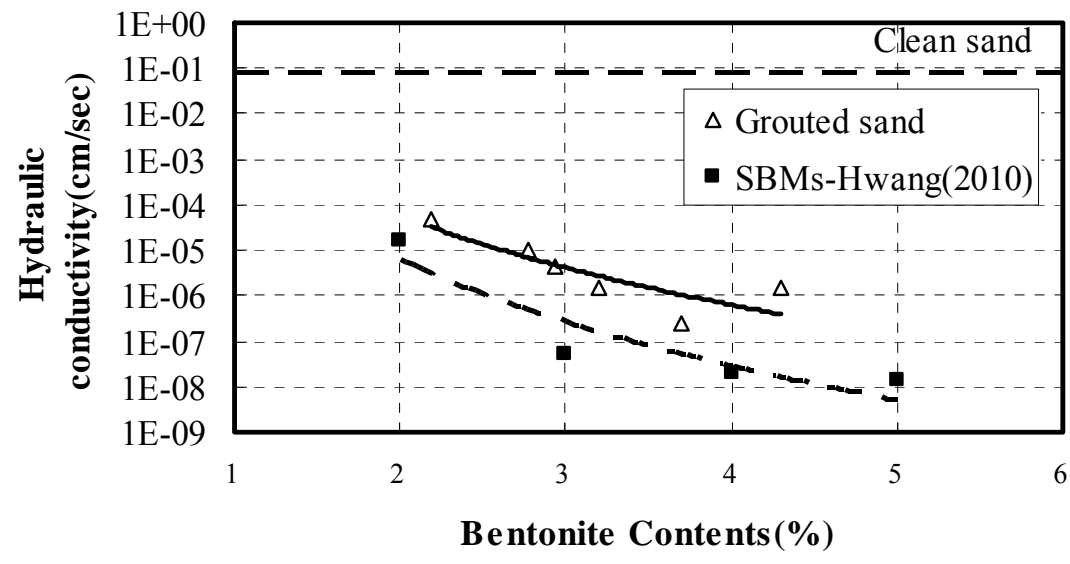

Figure 9. Hydraulic conductivity of the grouted sand with bentonite contents.

\section{CONCLUSIONS}

The yield stress and viscosity of various bentonite suspensions were measured to investigate applicability of these suspensions for permeation grouting. The addition of Sodium Pyrophosphate reduced the initial viscosity and yield stress, resulting in an increase in the mobility of the bentonite grouts. With the addition of SPP, high concentration bentonite grouts (up to $12 \%$ by dry mass) were flushed through uniform fine sand resulting in higher concentrations of bentonite in the sand. This permeation grouting method reduced the hydraulic conductivity of clean sand by 4, 4.5, and 5 orders magnitude with $7.5,10$, and $12 \%$ bentonite suspensions, respectively. Thus, this study shows that when controlling the viscosity and yield stress of bentonite suspensions, it is possible to permeate high concentration grouts into sand to control the hydraulic conductivity.

\section{REFERENCES}

Abend, S., and Lagaly, G. (2000). "Sol-gel transitions of sodium montmorillonite dispersions." Applied Clay Science, 16(3-4), 201-227.Chapuis, R. (2002). "The 2000 RM Hardy Lecture: Full-scale hydraulic performance of soilbentonite and compacted clay liners." Canadian Geotechnical Journal, 39(2), 417-439.

Abichou, T., Benson, C. H., and Edil, T. B. (2000). "Foundry Green Sands as Hydraulic Barriers: Laboratory Study." Journal of Geotechnical and Geoenvironmental Engineering, 126(12), 1174-1183.

Barnes, H., and Carnali, J. (1990). "The vane-in-cup as a novel rheometer geometry for shear thinning and thixotropic materials." Journal of Rheology, 34, 841.

Chapuis, R. (2002). "The 2000 RM Hardy Lecture: Full-scale hydraulic performance of soil-bentonite and compacted clay liners." Canadian Geotechnical Journal, 39(2), 417-439. 
Chegbeleh, L., Nishigaki, M., Akudago, J., and Katayama, T. (2009). "Experimental study on ethanol/bentonite slurry injection into synthetic rock fractures: Application to seepage control." Applied Clay Science, 45(4), 232-238.

Chun, B., Lee, Y., and Chung, H. (2006). "Effectiveness of leakage control after application of permeation grouting to earth fill dam." KSCE Journal of Civil Engineering, 10(6), 405-414.

Clarke, J. P. (2008). "Investigation of Time-Dependent Rheological Behavior of Sodium Pyrophosphate-Bentonite Suspensions." Purdue University, West Lafayette, Indiana, p.58.

Gonzalez, J. and Martfn-Vivaldi, J. (1963). "Rheology of bentonite suspensions as drilling muds." Stockholm, Sweden.

Hwang, H. (2010). "The effects of prehydration on hydraulic conductivity of SBMs." The University of Texas at Austin, Austin, TX.

Jessen, F and Turan, F. (1961). ""Deflocculation of fractionated montmorillonite by sodium polyphosphates." Society of Petroleum Engineers Journal, 1(4), 229234

Kazemain, S. and Huat, B.B.K. (2009). "Assessment and comparison of grouting and injection methods in geotechnical engineering." European Journal of Scientific Research, 27(2), 234-247.

Metcafle, R. and Walker (2004). "Bentonite-cement interaction in repository environments." Proceedings of the international workshop, 14-16 April 2004, Tokyo, NUMO-TR-04-05, Nuclear Waste Management Organization of Japan, Tokyo, pp 27-29, 43

Mitchell, J. and Soga, K. (1976). Fundamentals of soil behavior, Wiley New York.

Rugg, Dennis (2010). "Undrained monotonic shear strength of loose saturated sand treated with thixotropic bentonite suspension for soil improvement." The University of Texas at Austin, Austin, TX.

Tchillingarian, G. (1952) "Study of the dispersing agents." Journal of Sedimentary Petrology, 22(4), 229-233.

Weaver, K. (1993). "Some considerations for remedial grouting for seepage control." GEOTECH SPEC PUBL, ASCE, NEW YORK, NY(USA), 1993(35), 256-266.

Zhu, L., Sun, N., Papadopoulos, K., and De Kee, D. (2001). "A slotted plate device for measuring static yield stress." Journal of Rheology, 45, 1105. 